\title{
The solar cycle effect on the atmosphere as a scintillator for meteor observations
}

\author{
Asta Pellinen-Wannberg ${ }^{1}$, Edmond Murad ${ }^{2}$, Noah Brosch $^{3}$, \\ Ingemar Häggström ${ }^{4}$, and Timur Khayrov ${ }^{5}$ \\ ${ }^{1}$ Umeå University and Swedish Institute of Space Physics, \\ Box 812, SE-98128 Kiruna, Sweden \\ email: asta@irf.se \\ ${ }^{2}$ Retired AFRL, \\ 20 Kenrick Terrace, Newton, MA 02458 USA \\ email: emurad@verizon.net \\ ${ }^{3}$ The Wise Observatory and Tel Aviv University, \\ Tel Aviv 69978, Israel \\ email: noah@wise.tau.ac.il \\ ${ }^{4}$ EISCAT Headquarters, \\ Box 812, SE-98128 Kiruna, Sweden \\ email: ingemar@eiscat.se \\ ${ }^{5}$ Luleå University of Technology and Julius Maximilians Universität Würzburg, \\ Box 812, SE-98128 Kiruna, Sweden \\ email: timkha-6@student.Itu.se
}

\begin{abstract}
We discuss using high solar cycle atmospheric conditions as sensors for observing meteors and their properties. High altitude meteor trails (HAMTs) have sometimes been observed with HPLA (High Power Large Aperture) radars. At other times they are not seen. In the absence of systematic studies on this topic, we surmise that the reason might be differing atmospheric conditions during the observations. At EISCAT HAMTs were observed in 1990 and 1991. Very high meteor trails were observed with Israeli L-band radars in 1998, 1999 and 2001. Through the Leonid activity, around the latest perihelion passage of comet Tempel-Tuttle, optical meteors as high as $200 \mathrm{~km}$ were reported. This was partly due to new and better observing methods. However, all the reported periods of high altitude meteors seem to correlate with solar cycle maximum. The enhanced atmospheric and ionospheric densities extend the meteoroid interaction range with the atmosphere along its path, offering a better possibility to distinguish differential ablation of the various meteoric constituents. This should be studied during the next solar maximum, due within a few years.
\end{abstract}

Keywords. Sun: activity, solar-terrestrial relations, atmospheric effects, meteors, meteoroids

\section{Introduction}

Until quite recently it was considered that meteoroid ablation starts below $130 \mathrm{~km}$. At the time of the last apparition of comet 55P/Tempel-Tuttle, parent of the Leonids, however, many high altitude optical meteors were reported. This might be due to new and improved methods such as intensified TV observations, which have recorded meteors up to $160 \mathrm{~km}$ altitude (Fujiwara et al. 1998). Koten et al. (2006) reported 164 meteors with beginning heights above $130 \mathrm{~km}$ from Leonids in 1998-2001. The altitude $130 \mathrm{~km}$ is often given as the limit above which the dominating process of sputtering from the meteoroid surface due to the neutral and ionized atmospheric constituents switches over to ablation. 
Table 1. High altitude meteor trails

\begin{tabular}{ccc}
\hline Date & Time $[\mathbf{U T}]$ & Altitude $[\mathrm{km}]$ \\
\hline $1990-12-12$ & $19: 24: 52$ & 139 \\
$1990-12-12$ & $19: 24: 52$ & 154 \\
$1990-12-12$ & $20: 14: 46$ & 160 \\
$1990-12-13$ & $01: 11: 17$ & 160 \\
$1990-12-13$ & $01: 11: 54$ & 160 \\
$1990-12-13$ & $02: 13: 42$ & 147 \\
$1990-12-14$ & $19: 10: 32$ & 133 \\
$1990-12-14$ & $22: 00: 24$ & 111 \\
$1990-12-14$ & $22: 33: 44$ & 141 \\
$1990-12-14$ & $23: 19: 10$ & 223 \\
$1990-12-14$ & $23: 28: 14$ & 214 \\
$1990-12-15$ & $00: 01: 54$ & 138 \\
$1990-12-15$ & $02: 44: 12$ & 142 \\
$1990-12-15$ & $02: 54: 10$ & 134 \\
\hline
\end{tabular}

It is known that the altitude at which meteor phenomena are observed depends on the characteristics of the meteoroid, for example mass, density, entry velocity, impact angle, structure and composition. In addition to the observation method, variations in the atmospheric and ionospheric altitude density profiles contribute to the altitude profiles of meteors. Thus the meteor beginning altitudes vary between high and low latitudes, time of day and season. The dominant effect might, however, be due to the 11-year solar cycle which decreases and increase the comparable densities of the Earth's atmosphere. An essential issue here is that the recent Leonid activity reached its maximum simultaneously with the latest solar cycle 23 around 1999-2002. This feature might contribute to the many reports on high altitude meteors. In this paper we discuss the impact of the solar cycle variations on the atmospheric density profiles in some radar and visual meteor observations.

\section{Meteor altitudes}

The first high altitude meteor trails (HAMTs) were recorded with the EISCAT UHF radar during the initiation of meteor observations at the facility in 1990 and 1991. Typically these events lasted a few seconds, but events lasting up to 14 seconds were also recorded. They were interpreted as trails drifting through the antenna beam (PellinenWannberg and Wannberg, 1996). Table 1 summarizes the observations.

The first published HAMTs extended up to $400 \mathrm{~km}$ during the 1998 and 1999 Leonids (Brosch et al. 2001). The measurements were performed with the L-band Israeli phased array radar facility. In a later search through 2005-2006 EISCAT common program data no HAMTs were found (Khayrov 2008). Neither were they seen in a dedicated EISCAT TNA campaign by Brosch et al. (2009).

The common item with the EISCAT 1990 and 1991 measurements and the Israeli 1998 and 1999 observations is that they both occured during high solar activity, while the later reconstructions were performed close to the present exceptionally quiet solar minimum. At EISCAT there were no common programs optimized for such searches before 2005 . The 1990 and 1991 observations were highly focused special programs, which were not run later when studying head echoes.

Head echo distributions also show altitude variations, though on a smaller scale. Westman (1997) proposed that there is a seasonal variation in meteor head echo altitude distributions, which also depends on the frequency. The concept of a "head echo height ceiling" was introduced for the altitude below which $90 \%$ of the head echoes occurred. The wintertime distributions from December 1990 and 1991 are 2-4 km higher up than 
the summertime one from August 1993. This feature was associated with the seasonal variation of the atmospheric density.

Sparks and Janches (2009) have published diurnal as well as seasonal variations in micrometeor (i.e. head echo) altitude distribution peaks from Arecibo at $18.3^{\circ} \mathrm{N}$ and PFISR at $65.1^{\circ} \mathrm{N}$. The seasonal variation is small in the tropics, but the diurnal variation can be as large as $10 \mathrm{~km}$. The high latitude observations show the opposite, the diurnal variation is smaller and the winter distributions are about six $\mathrm{km}$ higher than the summer ones. The authors correlated the results with the astronomical properties of the meteoric flux.

Khayrov (2008) compared the Westman (1997) results with EISCAT common program data from 2005 and 2006 . These were $3-5 \mathrm{~km}$ lower down than the distributions from the early 90's, but the wintertime distribution was still 3-4 km higher up than the summer ones, as in the earlier data. The 1990/91 observations were performed during high and the 2005/06 observations during low solar activity. Thus these altitude differences might be related to the variations in atmospheric densities due to the solar cycle.

During the 2002 meteor shower a Leonid starting at $145 \mathrm{~km}$ was observed with the ALIS optical network operating CCD imagers in Northern Sweden (Pellinen-Wannberg et al. 2004). The signal was recorded in two imagers. One of them had a sodium filter allowing emissions at $589.3 \pm 10.0 \mathrm{~nm}$ and the second one had a calcium filter $422.7 \pm$ $14.0 \mathrm{~nm}$ also covering iron and Balmer hydrogen gamma emissions. The Leonid trail through the second filter was very strong and started at $145 \mathrm{~km}$ altitude, while the one in the usually stronger sodium line was much weaker and started at $110 \mathrm{~km}$. Thus it was assumed that the strong emission came from the hyper-thermal collisions between a hydrogen compound in the meteoroid with the atmospheric constituents. This Leonid came from the 55P/Tempel-Tuttle 1767 trail and had traveled seven orbits after its ejection from the comet. Thus it was possible that it still contained ice at entry into Earth's atmosphere if a fast rotating grain with albedo 0.1 is assumed.

\section{The expanding atmosphere}

The enhanced solar activity causes the atmosphere, as well as the ionosphere, to expand to higher altitudes. This is known in connection with the enhanced drag on satellites, and accelerated orbital decay. The atmospheric density profiles can be estimated from

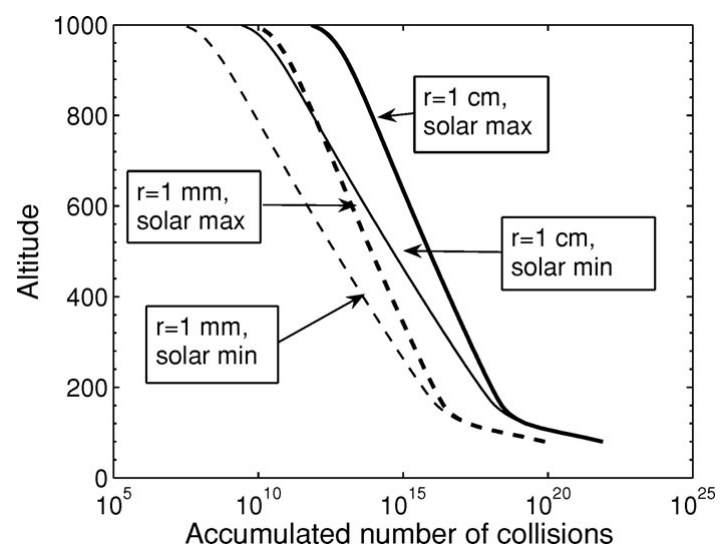

Figure 1. The accumulated number of collisions of a $1 \mathrm{~cm}$ (solid line) and a $1 \mathrm{~mm}$ (dashed) radius meteoroid with the atmospheric constituents during solar maximum (bold) and minimum conditions at $60^{\circ} \mathrm{N}$ and $20^{\circ} \mathrm{E}$ 
the MSIS model (Hedin 1991) for given latitude and time, which includes the time of day, season and solar cycle. For example, at $200 \mathrm{~km}$ during the solar cycle maximum the atomic $\mathrm{O}$ density is on average as high as the density about $20 \mathrm{~km}$ lower down during the minimum. At $150 \mathrm{~km}$ the difference is about $5 \mathrm{~km}$. At $400 \mathrm{~km}$ this altitude difference is close to $100 \mathrm{~km}$. For the ionospheric part of the atmosphere the situation is more complicated and the altitude differences can be even larger.

For studying the meteoroids' interaction with the atmosphere, another parameter might be more relevant. The meteoroids' accumulated collisions with the atmospheric constituents is shown in Fig. 1. The number of collisions of a $1 \mathrm{~cm}$ and a $1 \mathrm{~mm}$ size meteoroid is the same at $185 \mathrm{~km}$ at solar maximum as it is at $150 \mathrm{~km}$ at the minimum; at $130 \mathrm{~km}$ the difference is only about $5 \mathrm{~km}$. At $400 \mathrm{~km}$ the difference is again about $100 \mathrm{~km}$. Since the meteoroid temperature is related to the start of the observable meteor process and the body is heated up due to every collision, comparable meteors can flame up earlier during solar maximum than minimum conditions.

\section{Summary}

The atmospheric density has an impact on both meteor trail and head echo beginning heights. The extreme variations of atmospheric densities differ from a few kilometers to $100 \mathrm{~km}$ for solar min and max conditions. This might contribute to the explanation of appearance of the HAMTs in 1990 and 1991 at EISCAT and many of the high altitude Leonids around the latest perihelion passage during solar cycle maximum. The prevalent atmospheric density profile of the time and location should be related to the micrometeor altitude distributions as well as trail echo observations. The condition of the expanded atmosphere during the coming solar cycle maximum might systematically be used as a "scintillator" for detecting various features of impacting meteors within an essentially longer path than during solar minimum. Appearance of various type of constituents, which under low activity disintegrate together below $130 \mathrm{~km}$ altitude, can occur differentially at higher altitudes in solar maximum. Even volatiles locked in the meteoroid structures can be released at higher altitudes, which might explain the Leonid observed in 2002 (Pellinen-Wannberg et al. 2004) and other HAMTs during the past Leonids. A in-depth study has been initiated to investigate the solar cycle effect on meteor properties including chemical reactions between the meteoroid and atmospheric constituents.

\section{References}

Brosch, N., Schijvarg, N., Podolak, M., \& Rosenkrantz, M. R. 2001, in: B. Warmbein (ed.), Proceedings of the Meteoroids 2001 Conference (ESA Publications Division), pp. 165-173

Brosch, N., Häggström, I., Pellinen-Wannberg, A., \& Westman, A. 2009, MNRAS, in press

Fujiwara, Y., Ueda, M., Shiba, Y., Sugimoto, M., Kinoshita, M, \& Shimoda, C. 1998, J. Geophys. Res., 25, 285

Hedin, A. E. 1991, J. Geophys. Res., 96, 1159

Khayrov, T. 2008, MSc Thesis LTU, ISSN 1653-0187, ISNB LTU-PB-EX-09/016-SE

Koten, P., Spurný, P., Borovička, J. Evans, S., Elliott, A., Betlem, H., Štork, R., \& Jobse, K. 2006, Meteorit. Planet. Sci., 40, 1635

Pellinen-Wannberg, A., \& Wannberg, G. 1996, J. Atmos. Terr. Phys., 58, 495

Pellinen-Wannberg, A., Murad, E., Gustavsson, B., Brändström, U., Enell, C.-F., Roth, C., Williams, I. P., \& Steen, A. 2004, Geophys. Res. Lett., 31, doi: 10.1029/2003GL018785

Sparks, J. J., \& Janches, D. 2009, Geophys. Res. Lett., 36, doi: 10.1029/2009GL038485

Westman, A. 1997, PhD Thesis IRF Scientific Report, ISSN 0284-1703, ISNB 91-7191-351-3 